\title{
Molecular Characterization and Genetic Diversity of Aman Rice (Oryza sativa L.) Landraces in Bangladesh
}

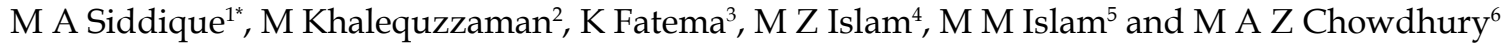

\begin{abstract}
Assessment of genetic diversity and molecular characterization among rice landraces of Bangladesh is important for their identification. Genetic diversity of 96 Aman (rainfed, partially irrigated) rice landraces of Bangladesh were evaluated using eight SSR markers to characterize the landraces and also to establish the sovereignty of Bangladeshi rice gene pool. A total of 159 alleles were detected. The number of alleles per locus ranged from 13 (RM60, RM237) to 34 (RM163), with an average of 19.88. The polymorphism information content (PIC) which ranged from 0.86 (RM237) to 0.95 (RM163) with an average of 0.90 revealed much variation among the studied landraces. RM163 was the best marker for identification and diversity estimation of Aman rice landraces as revealed by PIC values. The allele frequency ranged from $8.33 \%$ (RM163) to $22.92 \%$ (RM60, RM125) with an average of 15.89. The UPGMA dendrogram based on Nei's genetic distance revealed seven distinct clusters with a similarity coefficient of 0.09. The two-dimensional graphical view of Principal Coordinate Analysis (PCoA) revealed that the landraces Pankaij, Lotha, Chinigura, Patjag, Chinikanai, Badshabogh, Panati, Jirasail, Joria, Dudhmoni, Jhingasail were found far away and distributed around the centroid of the cluster. The findings of this study are useful for landraces identification to assist plant breeders in selecting suitable genetically diverse parents for breeding programmes.
\end{abstract}

Key words: Allele, gene pool, polymorphism, genetic diversity, SSR markers

\section{INTRODUCTION}

Rice (Oryza sativa L.) is an important cereal crop grown exclusively for human consumption that is the staple food for about $50 \%$ of the global population (Garris et al., 2005; Ramkumar et al., 2010). It has been cultivated in Asia since ancient times and for generations farmers have maintained thousands of different landraces (Jackson, 1995). Now, 90\% of world rice is produced in Asia on an area of almost 150 million hectares. Rice accounts for $50 \%$ of agricultural income in Asia and supplies almost $80 \%$ of the region's nutrition. In Bangladesh rice engages more than $70 \%$ of the rural population and is central to agriculture and the national economy (Anonymous, 2002). This crop provides about 75 and 55\%, respectively, of the calorific and protein content of the average daily human diet.
Due to great significance and intimate association of rice in food security and local ways of life and culture, Asian farmers have selected and maintained a vast array of rice landraces over thousands of years. Scientists estimate that more than 1,40,000 rice varieties have been developed/selected/isolated in Asia. More than 1,27,000 rice accessions and wild relatives can be found in the world's largest Genebank for rice at IRRI (International Rice Research Institute) located in the Philippines (http:// irri.org/our-workresearch/genetic-diversity). Until now, Bangladesh Rice Research Institute (BRRI) has collected and preserved more than 8,000 varieties/landraces/cultivars/wild types from indigenous and exotic sources in the Genebank. Out of them, 8,044 landraces have been registered. 
Research has been conducted on Bangladeshi local landrace in the world by many scientists, but research on indigenous landraces in BRRI is very limited. Only few years ago a large number of farmers grew these local cultivars as their main crop. These cultivars have good adaptation but are poor yielder. Actually, cultivation of these landraces gradually has been replaced through high yielding varieties over the last 20 years. In Bangladesh, rice is grown in three seasons namely Aus, Aman and Boro. BRRI Genebank is enriched with about 4,990, 1,670, 1,350 rice accessions for Aman, Boro and Aus season, respectively. They are adapted in different parts of the country, some of which have very nice quality, fineness, aroma, taste and high protein content (Dutta et al., 1998). After establishment of BRRI, characterization or DNA fingerprinting has been done only for a small number of local landraces. Many countries in the world have characterized their indigenous different crop landraces at both molecular and phenotypic level. This has been done for keeping their crop identity and for searching new genes for further crop improvement. But information about the genetic diversity of local landraces as well as Aman rice is very limited. The needs for varietal improvement for such situations are very important. Precise information about the extent of genetic diversity among population is crucial in any crop improvement programme, because selection of plants based on genetic diversity has become successful in several crops (Ananda and Rawat, 1984; De et al., 1988). Genetic diversity in any crop is basically important for improving heterotic crop genotypes over the existing ones. Therefore, research emphasis has been given on genetic diversity for micro-satellite DNA markers in local Aman rice landraces.

Molecular markers have successfully been applied in registration activities of cultivars (Mailer et al., 1994) and also identification of varieties as a part of seed and grain trade (Bligh et al., 1999). A powerful technique for DNA fingerprinting is the Polymerase Chain Reaction (PCR) amplification of tandem repeat sequences. This has long been known to be polymorphic and widespread in plant genomes and is referred to as Simple Sequence Repeats (SSR) or Micro-satellite polymorphism (Cregan, 1992; Morgante and Olivieri, 1993). It has been demonstrated that SSRs are highly informative, locus specific markers in many species of plants (Akkaya et al., 1992; Legarcrantz et al., 1993; Wu and Tanksley, 1993; Rahman et al., 2007). The user-friendly nature of SSR markers was successfully exploited in many crop species for a better understanding of the genetic diversity, domestication process and geographic divergence and distribution. SSRs are increasingly useful for integrating the genetic, physical, and sequence-based maps of rice, and they simultaneously provide breeders and geneticists with an efficient tool to link phenotypic and genotypic variation.

In rice, micro-satellites are abundant and well distributed throughout the genome $(\mathrm{Wu}$ and Tanksley, 1993; Akagi et al., 1996; McCouch et al.,1997). They are valuable as genetic markers because they are co-dominant in nature, detect high levels of allelic diversity and are assayed efficiently by the PCR technique (McCouch et al., 2002). The level of average genomewide coverage provided by micro-satellites in rice, one marker every 6 centimorgans (Temnykh et al., 2000), was sufficient to be useful for assessment of hybrid seed purity and for genotype identification. Akagi et al. (1997) suggested that hyper-variable microsatellites could be used to classify individual rice cultivars and to maintain the purity of rice seeds by eliminating contamination. This technique has been used for characterization and documentation in 20 crop species including rice, wheat, maize, barley, rapeseed, soybean, potato and other crops by Rahman et al. (2006, 2007). Reports also reveal that microsatellites have been used for rice variety/ cultivar identification in Bangladesh (Rahman et al., 2006, 2007 and 2008). Based on the above reports, the present study was designed with 96 Aman rice germplasm using molecular traits for characterization and diversity analysis. The objectives of this research were to: (1) assess the genetic variation and diversity of 96 Aman rice landraces, (2) determine the genetic relationship among these landraces for breeding purposes, and (3) characterize them. 
MATERIALS AND METHODS

Plant materials

Ninety-six Aman rice landraces of Bangladesh were studied (Table 1). A five gram seed from each of the entry was germinated and then sown in earthen ware pots for growth and subsequent DNA extraction.

Table 1. Rice cultivars used in the present study with their provenance.

\begin{tabular}{|c|c|c|c|c|c|}
\hline Variety & BRRI accession no. & Place of collection & Variety & BRRI accession no. & Place of collection \\
\hline Biruin & 4887 & Sherpur & Chinikanai & 4356 & Khulna \\
\hline Kalijira & 4755 & Barguna & Panati & 4090 & Nilphamari \\
\hline Topa & 962 & Khulna & Horibhogh & 977 & Khulna \\
\hline Chinigura & 4867 & Mymensingh & Akhnisail & 3446 & Sylhet \\
\hline Chamara & 2006 & Mymensingh & Ratisail & 876 & Sylhet \\
\hline Patjagh & 3647 & Pabna & Gochisail & 4877 & Mymensingh \\
\hline Aloi & 4866 & Mymensingh & Varisail & 900 & Sylhet \\
\hline Sadamota & 1576 & Patuakhali & Laki & 910 & Sylhet \\
\hline Lalmota & 1583 & Patuakhali & Gandhi biruin & 5986 & Sylhet \\
\hline Khama & 1456 & Dhaka & Tolabiruin & 833 & Sylhet \\
\hline Bajal & 2044 & Satkhira & Hashim & 7282 & Mymensingh \\
\hline Dadkhani & 6721 & Rajbari & Jhoria & 860 & Sylhet \\
\hline Bashful & 1508 & Bakerganj & Kataribhogh & 4791 & Dinajpur \\
\hline Binni & 4477 & Sherpur & Jirasail & 6718 & Naogaon \\
\hline Tulshimala & 3671 & Kishoreganj & Badshabhogh & 3 & Dhaka \\
\hline Joina & 5315 & Bagerhat & Daudin & 14 & Dhaka \\
\hline Parangi & 7273 & Faridpur & Dudsar & 21 & Dhaka \\
\hline Horkoch & 4772 & Khulna & Dhepi & 23 & Dhaka \\
\hline Bekibalam & 5304 & Khulna & Hatisail & 31 & Dhaka \\
\hline Ashfol & 4842 & Satkhira & Jessobalam & 34 & Dhaka \\
\hline Chapail & 2018 & Khulna & KhiraiJali & 40 & Dhaka \\
\hline Chengai & 3858 & Barisal & Latisail & 43 & Dhaka \\
\hline Jalpaira & 5303 & Khulna & Nizersail & 49 & Dhaka \\
\hline Latma & 5271 & Sunamganj & Patnai & 52 & Dhaka \\
\hline Nonakuchi & 5323 & Khulna & Rajasail & 57 & Barisal \\
\hline Birpala & 5320 & Jessore & SR-26-B & 59 & Dhaka \\
\hline Jamainaru & 4788 & Satkhira & Tilockachari & 61 & Dhaka \\
\hline Gandhokasturi & 5319 & Bagerhat & Lalrodadhan & 69 & Manikganj \\
\hline Sabrimaloti & 5342 & Bagerhat & Bhobanibhogh & 70 & Manikganj \\
\hline Jotabalam & 5341 & Khulna & Ratasail & 71 & Dhaka \\
\hline Patnai & 4843 & Satkhira & Lambosail & 73 & Munshiganj \\
\hline Godalaki & 25 & Sylhet & Ropaaman & 75 & Manikganj \\
\hline Dudlaki & 911 & Sylhet & Kartiksail & 76 & Manikganj \\
\hline LalAman & 44 & Habiganj & Lotha & 79 & Dhaka \\
\hline MaliaVhangor & 46 & Dhaka & Gangasagar & 80 & Munshiganj \\
\hline
\end{tabular}


Table 1. Continued.

\begin{tabular}{|c|c|c|c|c|c|}
\hline Madhumala & 395 & Rajshahi & Pankaij & 81 & Dhaka \\
\hline Gabura & 24 & Dhaka & Holidjaran & 82 & Manikganj \\
\hline Morichful & 74 & Dhaka & Apchaya & 83 & Manikganj \\
\hline Sakkorkhana & 7316 & Jhalakathi & Madhusail & 85 & Manikganj \\
\hline Kumragoir & 1047 & Khulna & Jamalbhogh & 86 & Dhaka \\
\hline Aloi & 2092 & Jamalpur & Arichadhigha & 87 & Manikganj \\
\hline Radhunipagol & 6711 & Rajshahi & Jhuldhigha & 88 & Manikganj \\
\hline Matorsail & 3294 & Sylhet & Boron & 90 & Manikganj \\
\hline Sitavhogh & 5317 & Bagerhat & Sechi & 93 & Dhaka \\
\hline Dudsail & 1023 & Khulna & Soider boron & 95 & Manikganj \\
\hline JiJhingasail & 35 & Dhaka & Lantkhama & 96 & Manikganj \\
\hline Dudhmoni & 1156 & Jessore & Hashfal boron & 97 & Manikganj \\
\hline Borondhan & 394 & Rajshahi & & & \\
\hline Fulkarai & 924 & Sylhet & & & \\
\hline
\end{tabular}

\section{SSR markers}

Eight SSR markers (Table 2) were used for diversity analysis.

\section{Genotyping}

Total genomic DNA was extracted from young leaves of three-week-old plants following the simple and modified protocol of Zheng et al., 1995. PCR analysis was performed in $12.5 \mu 1$ reaction sample containing 5-25 ng of DNA template, $1.25 \mu \mathrm{l}$ of $\mathrm{MgCl}_{2}$ free 10X PCR buffer $\left(100 \mathrm{mM}\right.$ Tris- $\mathrm{HCl} \mathrm{pH} 9.0$ at $25^{\circ} \mathrm{C}, 500 \mathrm{mM}$ $\mathrm{KCl}, 0.1 \%$ Triton $^{\circledR} \mathrm{X}-100$ and $\mathrm{H}_{2} \mathrm{O}$ ), $1.5 \mu \mathrm{l}$ of 25
$\mathrm{mM} \mathrm{MgCl}{ }_{2}, 0.25 \mu \mathrm{l}$ of $10 \mathrm{mM}$ dNTP, $0.25 \mu \mathrm{l}$ of $5 \mathrm{U} / \mu \mathrm{l}$ Taq polymerase enzyme, $0.625 \mu \mathrm{l}$ each of $10 \mu \mathrm{M}$ forward and reverse primers using a MJ Research single 96-well thermal cycler. The mixture was overlaid with one drop of mineral oil to prevent evaporation. After initial denaturation for five minutes at $94^{\circ} \mathrm{C}$, each cycle comprised one min denaturation at $94^{\circ} \mathrm{C}$, one min annealing at $55^{\circ} \mathrm{C}$, and two min extension at $72^{\circ} \mathrm{C}$ with a final extension for $7 \mathrm{~min}$ at $72^{\circ} \mathrm{C}$ at the end of 35 cycles. The PCR products were mixed with bromophenol blue gel loading dye and were analyzed by electrophoresis on $8 \%$ polyacrylamide gel using mini vertical

Table 2. List of the eight simple sequence repeat (SSR) markers.

\begin{tabular}{|c|c|c|c|c|}
\hline Locus name & Chr. & Repeat motif & Forward primer & Reverse primer \\
\hline RM60 & 3 & (AATT) $)_{5}$ AATCT(AATT) & CAAGTTCACCCGCCTTCTCG & TTTCCATCATTAGCAGGCAGTAGC \\
\hline RM163 & 5 & $\begin{array}{c}(\text { GGAGA })_{4} \\
(\mathrm{GA})_{11} \mathrm{C} \\
(\mathrm{GA})_{20}\end{array}$ & ATCCATGTGCGCCTTTATGAGGA & СGCTACСТССТTCACTTACTAGT \\
\hline RM218 & 3 & $\begin{array}{c}(\mathrm{TC})_{24} \mathrm{ACT}_{5} \\
(\mathrm{GT})_{11}\end{array}$ & TCAAACCAAGGTCCTTCAACTGC & TTTCTTCCACCGTCCATGTATCC \\
\hline RM237 & 1 & $(\mathrm{CT})_{18}$ & CAAATCCCGACTGCTGTCC & TGGGAAGAGAGCACTACAGC \\
\hline RM259 & 1 & $(\mathrm{CT})_{17}$ & GAAGTGCTCCCTAAACTTGTTGC & TTATGGAGGATGGATTCGAAGG \\
\hline RM125 & 7 & $(\mathrm{GCT})_{8}$ & ATCAGCAGCCATGGCAGCGACC & AGGGGATCATGTGCCGAAGGCC \\
\hline RM278 & 9 & $(\mathrm{GA})_{17}$ & GTAGTGAGCCTAACAATAATC & TCAACTCAGCATCTCTGTCC \\
\hline RM283 & 1 & $(\mathrm{GA})_{18}$ & GTCTACATGTACCCTTGTTGGG & CGGCATGAGAGTCTGTGATG \\
\hline
\end{tabular}


polyacrylamide gels for high throughput manual genotyping (CBS Scientific Co. Inc., CA, USA). $2.5 \mu \mathrm{l}$ of amplification products were resolved by running gel in 1x TBE buffer for 2-2.5 hrs depending upon the allele size at around 75 volts and $180 \mathrm{~mA}$ current. The gels were stained in $0.5 \mathrm{mg} / \mathrm{ml}$ ethidium bromide and were documented using UVPRO (Uvipro Platinum, EU) gel documentation unit. Microsatellite or simple sequence repeat (SSR) markers were used for molecular analysis (Temnykh et al., 2001; McCouch et al., 2002).

\section{Data analysis}

Molecular weight for each amplified allele was measured in base pair using Alpha-Ease 5.0 software. The summary statistics including the number of alleles per locus, major allele frequency, gene diversity, polymorphism information content (PIC) values were analysed using PowerMarker - 3.25 (Liu and Muse, 2005). For the unrooted phylogenetic tree, genetic distance was calculated using the "C.S. Chord 1967" distance measure (Cavalli-Sfoza and Edwards, 1967) followed by phylogeny reconstruction using neighbourjoining as implemented in PowerMarker using Treeview (Page, 1996). The allele frequency data were exported in binary format (allele presence $=" 1$ " and allele absence $=$ " 0 ") for analysis with NTSYS-pc version 2.2 (Rohlf, 2002). A similarity matrix was calculated with the Simqual subprogramme using the Dice coefficient, followed by cluster analysis with the SAHN subprogramme using the UPGMA (Unweighted pair group method using arithmetic mean) clustering method as implemented in NTSYS-pc. The similarity matrix was also used for principal coordinate analysis (PCoA) with the DCenter, Eigen, Output, and MXPlot subprogrammes in NTSYS-pc.

\section{RESULTS AND DISCUSSION}

\section{Overall SSR diversity}

Ninety-six rice landraces were successfully amplified with the eight micro-satellite markers where primer pairs referred to as loci and DNA bands as alleles. A total of 159 alleles were detected using eight micro-satellite markers across 96 rice landraces. The highest average band size was found for RM259 (173.09) followed by RM60 (169), and RM283 (149.44). Among the eight SSR markers, the highest number of alleles (34) were found for RM163 followed by RM259 (23); RM218 (22); RM278 (19); RM283 (18); RM125 (17); RM60, RM237 (13). The polymorphism information content (PIC) values ranged from 0.86 (RM237) to 0.95 (RM163), with an average of 0.90 . The allele frequency ranged from $8.33 \%$ (RM163) to $22.92 \%$ (RM60, RM125) with an average of 15.89 alleles. The PIC values for other markers were 0.92 (RM259, RM218, RM278), 0.91 (RM283), 0.88 (RM60) and 0.87 (RM125), respectively (Table 3). PIC value revealed RM163 as the best marker. Gene diversity varied from 0.87 to 0.95 and their average value was 0.91 , which also indicated the presence of adequate genetic diversity (Table 3). Figure 1 shows the DNA profiles of $96 \mathrm{~T}$. Aman landraces with SSR marker RM60.

\section{Genetic distance-based analysis}

The similarity matrix was constructed using Dice coefficient method. Cluster analysis was done to group the genotypes into a dendrogram. From this dendrogram, the 96 rice accessions were grouped into seven major clusters at a coefficient of 0.09 and the similarity coefficient value ranged from 0.06 to 0.75 . Cluster III consisted of 25 accessions and is the biggest group among seven clusters, followed by cluster II, which contained 22 accessions; cluster VI comprised 17 accessions; cluster IV comprised 14 accessions; cluster I and V were both composed of seven accessions; cluster VII had four accessions (Fig. 2). The genetic differences between 96 accessions were the highest between most of the landraces. Cent percent dissimilarity was found among the following 20 landrace combinations:

Biruin $\times$ Khama, Kalijira $\times$ Dadkhani, Topa $\times$ Bashful, Chinigura $\times$ Binni, Chamara $\times$ Joina, Parangi $\times$ Patjagh, Sadamota $\times$ Jotabalam, Tulsimala $\times$ Birpala, Horkoch $\times$ Rajasail, Sakkorkhana $\times$ Pankaij, Bajal $\times$ Godalaki, Patnai $\times$ Gandhokasturi, Gabura $\times$ Sabrimaloti, Kataribhog $\times$ Jhingasail, Radhunipagal $\times$ Kartiksail, Badshabhog $\times$ Chinikanai, Dhudsar $\times$ Latisail, Nizersail $\times$ Jamainaru, Lalmota $\times$ Laki, Maliavhangor $\times$ Ashfol. 
Table 3. Allele number, allele size, frequency, genetic diversity and PIC of $96 \mathrm{~T}$. Aman rice landraces for eight micro-satellite markers.

\begin{tabular}{lccccccc}
\hline Marker & Chr. No. & Position (cM) & Allele no. & Allele sizes (bp) & Allele freq (\%) & Genetic diversity & PIC value \\
\hline RM60 & 3 & 0.1 & 13 & 169 & 22.92 & 0.8861 & 0.8764 \\
RM163 & 5 & 91.4 & 34 & 147.68 & 8.33 & 0.9551 & 0.9532 \\
RM218 & 3 & 67.8 & 22 & 131.91 & 14.58 & 0.9264 & 0.9219 \\
RM237 & 1 & 115.2 & 13 & 129 & 17.71 & 0.8717 & 0.8584 \\
RM259 & 1 & 54.2 & 23 & 173.09 & 16.67 & 0.9266 & 0.9223 \\
RM125 & 7 & 24.8 & 17 & 120 & 22.92 & 0.8776 & 0.8669 \\
RM278 & 9 & 77.5 & 19 & 146.89 & 11.49 & 0.9262 & 0.9214 \\
RM283 & 1 & 31.4 & 18 & 149.44 & 12.50 & 0.9188 & 0.9131 \\
Mean & & & & & 15.89 & 0.9111 & 0.9042 \\
\hline
\end{tabular}

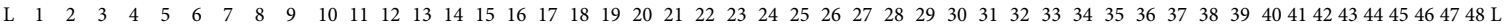

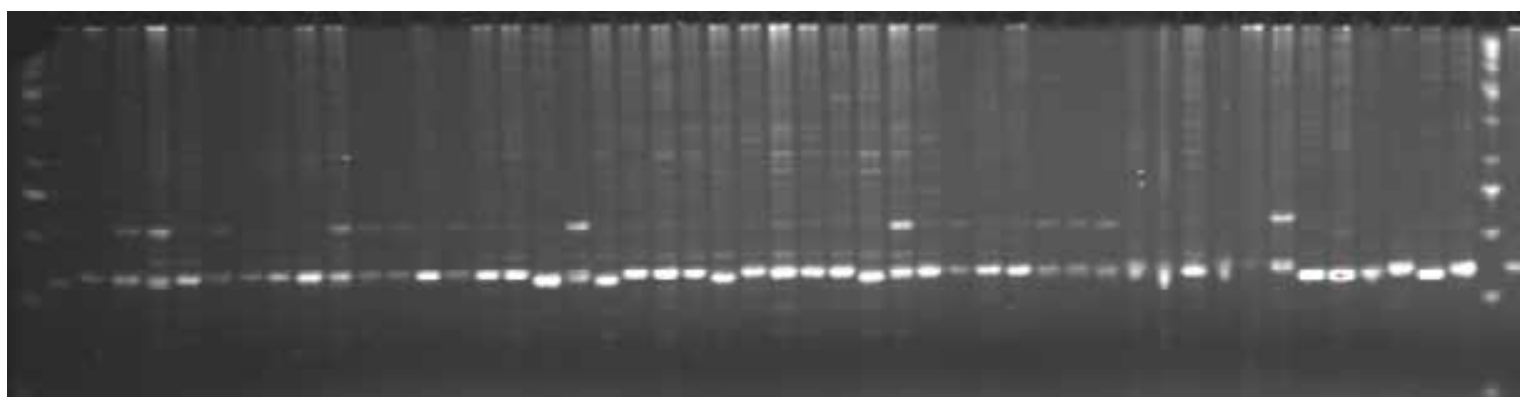

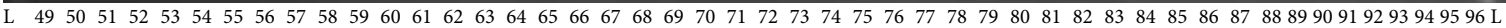

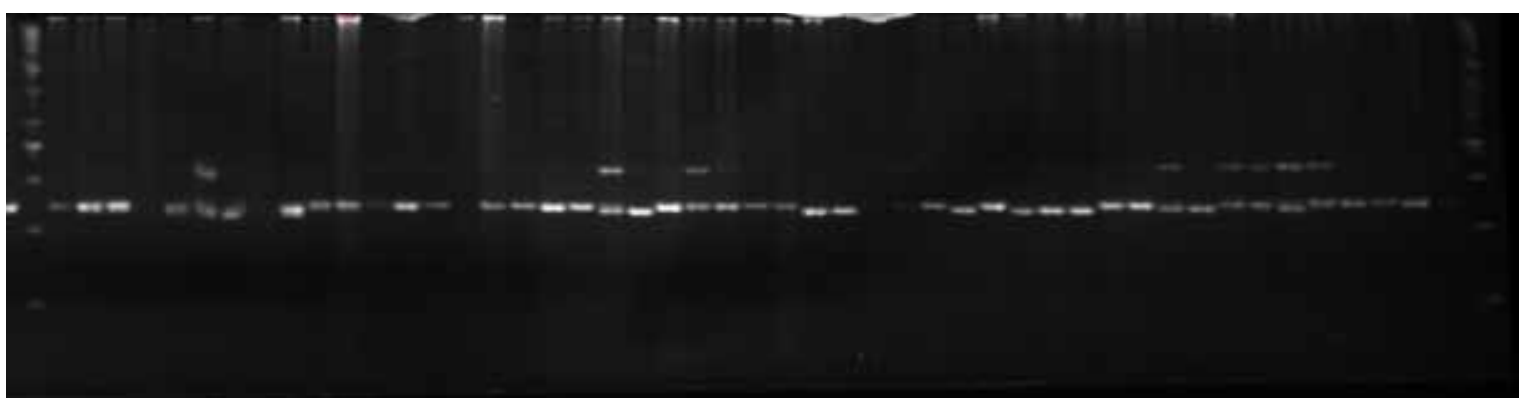

Fig. 1. DNA profile of 96 T. Aman landraces with RM60.

Legend: Lane1=Biruin, 2=Kalijira, 3=Topa, 4=Chinigura, 5=Chamara, 6=Patjagh, 7=Aloi, 8=Sadamota, 9=Lalmota, 10=Khama, 11=Bajal, 12=Dadjhani, 13=Bashful, 14=Binni, 15= Tulshimala, 16= Joina, 17= Parangi, 18=Horkoch, 19= Bekibalam, 20= Ashfol, 21=Chapail, 22=Chengai, 23=Jalpaira, 24=Latma, 25=Nonakuchi, 26=Birpala, 27=Jamainaru, 28=Gandhokasturi, 29=Sabrimalati, 30=Jatabalam , 31=Patnai, 32=Godalaki, 33=Dudlaki, 34=Lal aman, 35=Malia vhangor , 36=Madhumala, 37= Gabura, 38=Marichful, 39=Sakkorkhana, 40= Kumragori, 41=Aloi, 42=Radhunipagal, 43=Matorsail, 44=Sita vhogh, 45=Dudsail, 46=Jhingasail, 47= Dudmoni, 48=Boron dhan, 49=Fulkarai, 50=Chinikanai, 51=Panati, 52=Horovhogh, 53=Akhnisail, 54=Ratisail, 55=Gochisail, 56=Vorisail, 57=Laki, 58=Gandhi biruin, 59=Tola biruin, 60=Hashim, 61=Joria, 62=Katarivhogh, 63=Jirasail, 64=Badshavhogh, 65=Daudin, 66=Dudsar, 67=Dhepi, 68=Hatisail, 69=Jesso balam, 70=Khirai jali, 71=Latisail, 72=Nizersail, 73=Patnai-23, 74=Rajasail, 75=SR-26-B, 76=Tilocikachari, 77=Lal roda dhan, 78=Bhobanivhogh, 79=Ratasail, 80=Lambosail, 81=Ropa aman, 82=Kartiksail, 83=Lotha, 84=Gangasagar, 85=Pankaij, 86=Holid jaran, 87=Apchaya, 88=Madhusail, 89=Jamalbhogh, 90=Aricha digh, 91=Jhul digh, 92=Boron, 93=Sechi, 94=Soider boron, 95=Lani khama, 96=Hashfal boron. 


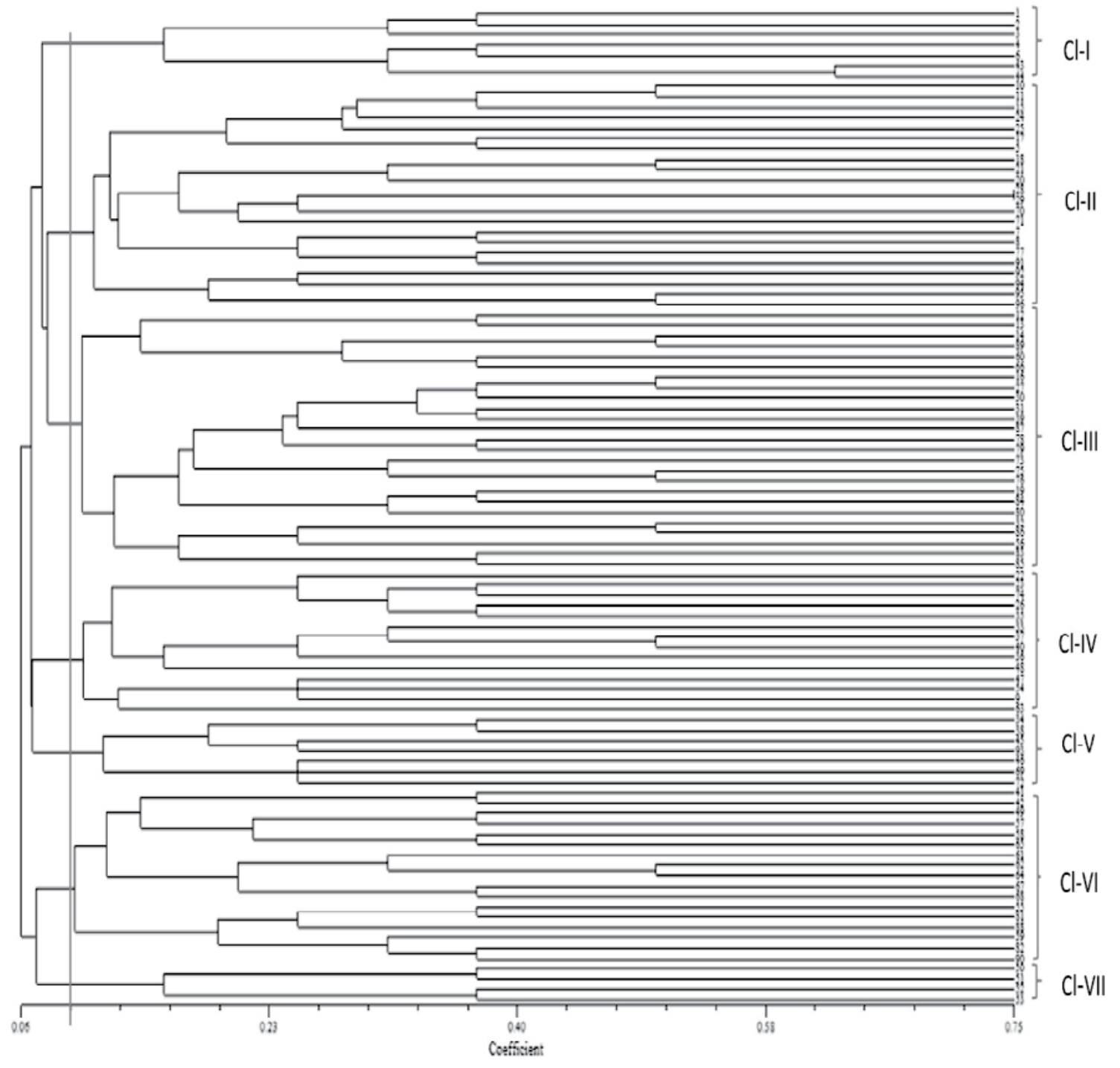

Fig. 2. An UPGMA cluster dendrogram showing the genetic relationships between 96 Aman rice landraces of Bangladesh based on the alleles detected by eight micro-satellite markers.

Legend: Lane1=Biruin, 2=Kalijira, 3=Topa, 4=Chinigura, 5=Chamara, 6=Patjagh, 7=Aloi, 8=Sadamota, 9=Lalmota, 10=Khama, 11=Bajal, 12=Dadjhani, 13=Bashful, 14=Binni, 15= Tulshimala, 16= Joina, 17= Parangi, 18=Horkoch, 19= Bekibalam, 20= Ashfol, 21=Chapail, 22=Chengai, 23=Jalpaira, 24=Latma, 25=Nonakuchi, 26=Birpala, 27=Jamainaru, 28=Gandhokasturi, 29=Sabrimalati, 30=Jatabalam , 31=Patnai, 32=Godalaki, 33=Dudlaki, 34=Lal aman, 35=Malia vhangor , 36=Madhumala, 37= Gabura, 38=Marichful, 39=Sakkorkhana, 40= Kumragori, 41=Aloi, 42=Radhunipagal, 43=Matorsail, 44=Sita vhogh, 45=Dudsail, 46=Jhingasail, 47= Dudmoni, 48=Boron dhan, 49=Fulkarai, 50=Chinikanai, 51=Panati, 52=Horovhogh, 53=Akhnisail, 54=Ratisail, 55=Gochisail, 56=Vorisail, 57=Laki, 58=Gandhi biruin, 59=Tola biruin, 60=Hashim, 61=Joria, 62=Katarivhogh, 63=Jirasail, 64=Badshavhogh, 65=Daudin, 66=Dudsar, 67=Dhepi, 68=Hatisail, 69=Jesso balam, 70=Khirai jali, 71=Latisail, 72=Nizersail, 73=Patnai-23, 74=Rajasail, 75=SR-26-B, 76=Tilocikachari, 77=Lal roda dhan, 78=Bhobanivhogh, 79=Ratasail, 80=Lambosail, 81=Ropa aman, 82=Kartiksail, 83=Lotha, 84=Gangasagar, 85=Pankaij, 86=Holid jaran, 87=Apchaya, 88=Madhusail, 89=Jamalbhogh, 90=Aricha digh, 91=Jhul digh, 92=Boron, 93=Sechi, 94=Soider boron, 95=Lani khama, 96=Hashfal boron. 


\section{Principal coordinate analysis}

The two-dimensional graphical view of principal coordinate Analysis (PCoA) showed the spatial distribution of the landraces along the two principal axes. The landraces Pankaij, Lotha, Chinigura, Patjag, Chinikanai, Badshabogh, Panati, Jirasail, Joria, Dudhmoni, Jhingasail were found far away from centroid of the cluster and the rest of the landraces were placed more or less around the centroid (Fig. $3)$. The results indicated that the landraces placed far away from the centroid were more genetically diverse while the landraces placed near around the centroid possessed more or less similar genetic background. However, centroid may be defined as the vector representing the middle point of the cluster, which contained at least one number for each variable. The connecting lines between each landrace and the centroid represented eigan vectors for the respective landraces.

The study of genetic diversity is a critical component of applied plant breeding for optimizing the choice of parents in a cropbreeding programme. An effective germplasm assessment provides the scientific basis for the selection of parents/donors for recombination breeding or hybrid breeding, and to breed

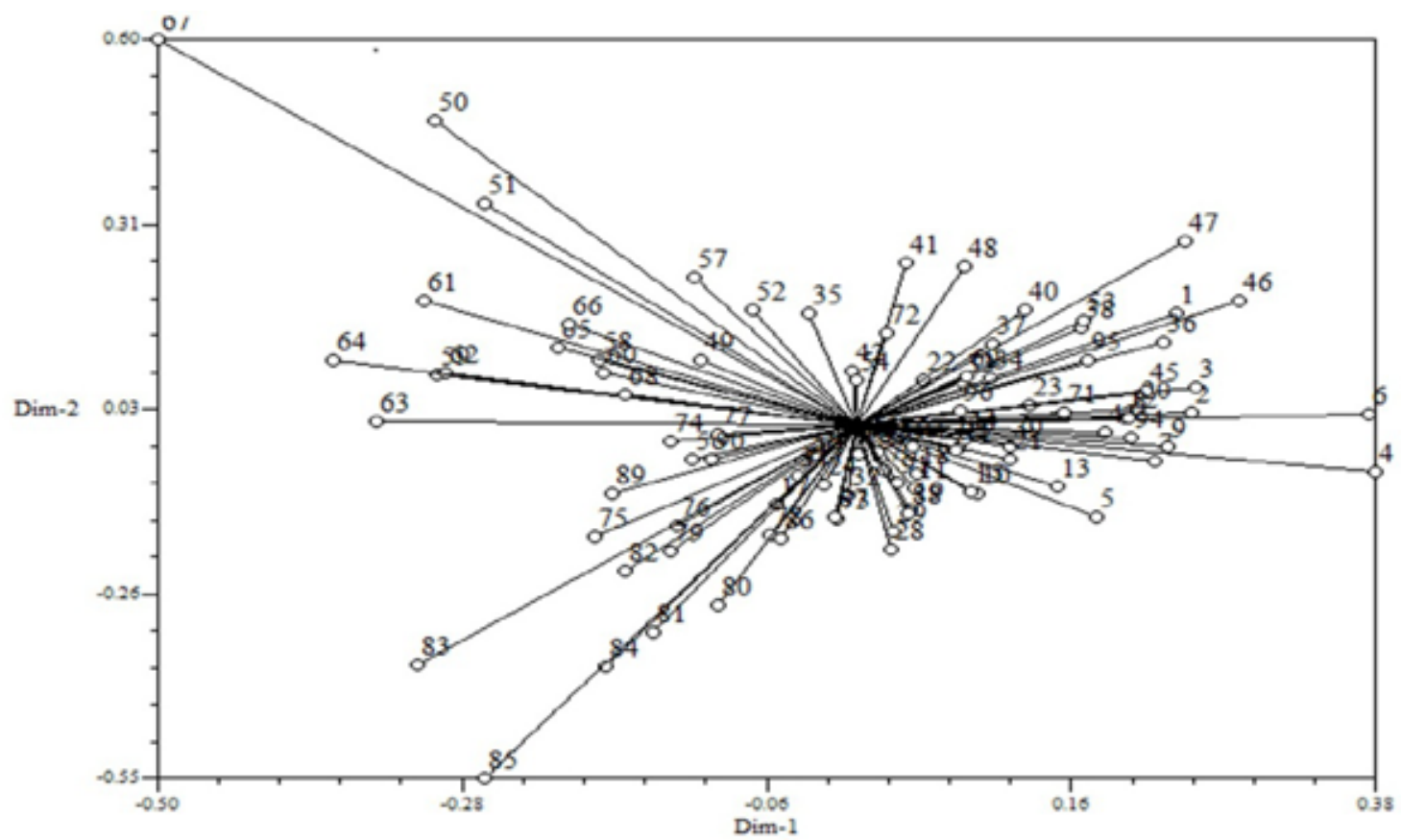

Fig. 3. Two-dimensional view of principal coordinate analysis (PCoA) with 8 micro-satellite markers over 96 Aman rice landraces.

Legend: Lane 1=Biruin, 2=Kalijira, 3=Topa, 4=Chinigura, 5=Chamara, 6=Patjagh, 7=Aloi, 8=Sada mota, 9=Lal mota, 10=Khama, 11=Bajal,12=Dadjhani,13=Bashful,14=Binni, 15= Tulshimala, 16= Joina, 17= Parangi,18=Horkoch, 19=Bekibalam, 20= Ashfol, 21=Chapail, 22=Chengai, 23=Jalpaira, 24=Latma, 25=Nonakuchi, 26=Birpala, 27=Jamainaru, 28=Gandhokasturi, 29=Sabrimalati, 30=Jatabalam , 31=Patnai, 32=Godalaki, 33=Dudlaki, 34=Lal aman, 35=Malia vhangor , 36=Madhumala, 37= Gabura, 38=Marichful, 39=Sakkorkhana, 40= Kumragori, 41=Aloi, 42=Radhunipagal, 43=Matorsail, 44=Sita vhogh, 45=Dudsail, 46=Jhingasail, 47= Dudmoni, 48=Boron dhan, 49=Fulkarai, 50=Chinikanai, 51=Panati, 52=Horovhogh, 53=Akhnisail, 54=Ratisail, 55=Gochisail, 56=Vorisail, 57=Laki, 58=Gandhi biruin, 59=Tola biruin, $60=$ Hashim, $61=J o r i a$, 62=Katarivhogh, 63=Jirasail, 64=Badshavhogh, 65=Daudin, 66=Dudsar, 67=Dhepi, 68=Hatisail, 69=Jesso balam, 70=Khirai jali, 71=Latisail, 72=Nizersail, 73=Patnai-23, 74=Rajasail, 75=SR-26-B, 76=Tilocikachari, 77=Lal roda dhan, 78=Bhobanivhogh, 79=Ratasail, 80=Lambosail, 81=Ropa aman, 82=Kartiksail, 83=Lotha, 84=Gangasagar, 85=Pankaij, 86=Holid jaran, 87=Apchaya, 88=Madhusail, 89=Jamalbhogh, 90=Aricha digh, 91=Jhul digh, 92=Boron, 93=Sechi, 94=Soider boron, 95=Lani khama, 96=Hashfal boron. 
for specific agro-ecological conditions and situations (Kumar et al., 2012). Diversity analysis at the molecular level using PCR-based markers is the efficient and rapid method of identifying the relationships and/or differences among the landraces (Schulman, 2007). Among the PCR-based markers, micro-satellites are becoming popular and suitable for largescale analysis, both for genetic diversity and breeding research (Brown and Kresovich, 1996; Joshi et al., 2000). Proficient and consistent use of molecular markers such as SSR for the study of genetic diversity in any food crop requires selection and application of primers, which will give clear, distinct, reliable and sufficient information required to study the divergence that occurs within the crop (Arolu et al., 2012). Distinct band patterns were produced from the studied SSR markers amplified among the 96 Aman rice accessions and it was possible to reveal polymorphism from each marker.

The observed PIC values ranged from 0.858 (RM237) to 0.953 (RM163) with a mean value of 0.904 . The allele frequency ranged from $8.33 \%$ (RM283) to 22.92\% (RM163, RM125) with an average of 15.89 . Our result is in agreement with the findings of Siddique et al. (2014), who estimated genetic diversity among T. Aman (rainfed lowland) rice germplasm using SSR markers. Gene diversity varied from 0.87 to 0.95 and their average value was 0.91 , which also indicated the presence of adequate genetic diversity (Table 3 ). This average value was higher than the value recorded in rice by Zaiquanetal. (2012) who found 0.33 and by Siddique et al. (2016) who found 0.83. A better resolution of the relationship among the 96 accessions was provided by the UPGMA cluster analysis using SSR markers. Seven major groups were found at similarity coefficient levels of 0.09 where the rice accessions were widely clustered (Fig. 3) and the similarity coefficient varied from 0.06 to 0.75 . It is notable that SSRs produced seven groups, but in the group of III the number of landraces was the highest (25) and the reason could be explained in this way that SSR markers might target a larger number of repeated sequences specifically in the centromeric region that might heavily influence the classification pattern (Parsons et al., 1997). These clustering patterns prove the acceptability and adaptability of SSR markers for the genetic diversity analysis among Aman rice germplasm. It was found that cluster analysis was profoundly supported by principal coordinate analysis (PCoA) but varied from unrooted neighbour-joining tree where six clusters were formed. The genetic diversity results that were observed under this study were supported by the consonance between cluster and PCoA analysis (Fig. 2-3).

\section{CONCLUSION}

Theresults obtained from thisstudy on molecular characterization provided some useful implications for establishment of sovereignty of Bangladeshi rice gene pool. There was a high level of genetic diversity among accessions of Aman rice. In this study, it is suggested that SSR markers were effective in the detection of polymorphism in this ecosystem. To broaden the genetic base and for the improvement of Aman rice, accessions having the lowest genetic similarities could be selected as parents. Therefore, hybridization may be made between two distant populations. Considering all these criteria and results from genetic diversity analysis, accessions that are far apart based on their genetic coefficient (like Biruin and Khama; Kalijira and Dadkhani; Bashful and Topa; Binni and Chinigura; Chamara and Joina; Patjag and Porangi; Sadamota and Jotabalam; Tulshimala and Birpala; Rajasail and Horkoch; Pankaij and Sakkorkhana) could be selected as parents for further breeding programmes.

\section{ACKNOWLEDGEMENT}

The authors are grateful to coordinated subproject on 'Characterization of important plant genetic resources' supported by World Bank through the NATP-SPGR, Bangladesh Agricultural Research Council for providing funds for this research. 


\section{REFERENCES}

Akagi, H, Y Yokozeki, AInagaki and T Fujimura. 1996. Micro-satellite DNA markers for rice chromosomes. Theor. Appl. Genet. 93: 1071-1077.

Akagi, H, Y Yokozeki, AInagaki and T Fujimura. 1997. Highly polymorphic micro-satellites of rice consist of AT repeats, and a classification of closely related cultivars with these micro-satellite loci. Theor. Appl. Genet. 94: 61-67.

Akkaya, M S, A A Bhagwat and P B Cregan. 1992. Length polymorphism of simple sequence repeat DNA in soybean. Genetics 132: 1131-1139.

Ananda, I J and D S Rawat. 1984. Genetic diversity, combining ability and heterosis in brown mustard. Indian J. Genet. 44: 226-234.

Anonymous, 2002. National Workshop on Rice Research and Extension-2002. Feeding the extra millions by 2025. Bangladesh Rice Res. Inst. Gazipur, p: 1.

Arolu, I W, M Y Rafii, M M Hanafi, T M M Mahmud and M A Latif. 2012. Molecular characterizations of Jatrophacurcas germplasm using inter simple sequence repeat (ISSR) markers in Peninsular Malaysia, Aust. J. Crop Sci. 6 (12): 1666-1673.

Bligh, H F J, N W Blackhall, K J Edwards and A M McClung. 1999. Using amplified fragment length polymorphisms and simple sequence length polymorphisms to identify cultivars of brown and white milled rice. Crop Sci. 39: 1715-1721.

Brown, S M and S K resovich. 1996. In: A H Paterson (Ed.), Genome mapping in plants, Clandes, New York, pp. 85-93.

Cavalli-Sforza, L L and A W F Edwards. 1967. Phylogenetic analysis. Models and estimation procedures. American Journal of Human Genetics 19(3 Pt 1): 233-257.

Cregan, P B. 1992. Simple sequence repeat DNA length polymorphisms. Probe 2: 18-22.

De, R N, R Setharam, M K Sinha and S P Banarjee. 1988. Genetic divergence in rice. Indian J. Genet. 48: 189194.

Dutta, R K, B P Lahiri and M A Baset Mian. 1998. Characterization of some aromatic and fine rice cultivars in relation to their physico-chemical quality of grains. Indian J. Plant Physil. 3(1): 61-64.

Garris, A J, T H Tai, J Coburn, S Kresovich and S McCouch. 2005. Genetic structure and diversity in Oryza sativa L. Genetics 169: 1631-1638.

Jackson, M T. 1995. Protecting the heritage of rice biodiversity. GeoJournal 35: 267-274.

Joshi, S P, V S Gupta, R K Aggarwal, P K Ranjekar and D S Brar. 2000. Genetic diversity and phylogenetic relationship as revealed by inter simple sequence repeat (ISSR) polymorphism in the genus Oryza. Theor. Appl. Genet. 100: 1311-1320.
Kumar, H, G Kaur and S Banga. 2012. Molecular characterization and assessment of genetic diversity in sesame (Sesamum indicum L.) germplasm collection using ISSR markers. J. Crop Improve. 26: 540-557.

Lagercrantz, U H Ellegren and L Andersson. 1993. The abundance of various polymorphic micro-satellite motifs differs between plants and vertebrates. Nucleic Acids Res. 21: 1111-1115.

Liu, K and S V Muse. 2005. PowerMarker: Integrated analysis environment for genetic marker data. Bioinformatics 21: 2128-2129.

Mailer, R J, R Scarth and B Fristensky. 1994. Discrimination among cultivars of rapeseed (Brassica napus L.) using DNA polymorphism amplified from arbitrary primers. Theor. Appl. Genet. 87: 697-704.

McCouch, S R, L Teytelman, Y Xu, K B Lobos, K Clare, M Walton, B Fu, R Maghirang, Z Li, Y Xing et al., 2002. Development and mapping of 2240 new SSR markers for rice (Oryza sativa L.). DNA Res. 9: 199-207.

McCouch, S R, X Chen, O Panaud, S Temnykh, Y Xu, Y G Cho, N Huang, T Ishii and M Blair. 1997. Micro-satellite marker development, mapping and applications in rice genetics and breeding. Plant Mol. Biol. 35(1/2): 89-99.

Morgante, M and A M Olivieri. 1993. PCR-amplified microsatellites as markers in plant genetics. Plant J. 3: 175-182.

Page, R D. 1996. Tree View: an application to display phylogenetic trees on personal computers. Comput. Mol. Biol. 12: 357-358.

Parsons, J B, H T Newbury, M T Jackson and B V Ford-Lloyd. 1997. Contrasting genetic diversity relationships are revealed in rice (Oryza sativa L.) using different marker types. Mol. Breeding 3: 115-125.

Rahman, L, M N Islam, M S Rahman, M S Islam, M Shah-eAlam and M K Bashar. 2008. Characterization of 94 rice (Oryza sativa L.) varieties of Bangladesh based on microsatellite loci. Bangladesh J. Agril. Sci. 35(1): 97-112.

Rahman, L, M R Molla, S Sultana, M N Islam, N U Ahmed, M S Rahman and M Nazim-ud-Dowla. 2007a. Plant varieties of Bangladesh: Morphological and molecular characterization. Published by Seed Wing, Ministry of Agriculture, Government of the Peoples' Republic of Bangladesh, Vol. 1, 486 p.

Rahman, L, M R Molla, S Sultana, M N Islam, N U Ahmed, M S Rahman, M Nazim-ud-Dowla, M Shah-E-Alam and M S Alam. 2006. Plant Varieties of BangladeshMorphological and Molecular characterization for plant variety protection. Bangladesh J. Agril. Sci. 33 (2): 215-225.

Rahman, M S, M R Molla, M S Alam and L Rahman. 2007b. DNA fingerprinting of rice (Oryza sativa L.) cultivars using micro-satellite markers. Poster presentation in the $1^{\text {st }}$ conference on "Promotion of Biotechnology in Bangladesh: National and International Perspectives", held on 06-08 April at the University of Dhaka, Bangladesh. http://promotebiotechbd. net/Abstract-book.pdf 
Rahman, M S, F Easmin, M S Islam, M A Samad and M S Alam. 2007c. Random amplified polymorphic DNA (RAPD) analysis in some indigenous aromatic rice (Oryza sativa L.) cultivars. Bangladesh J. Crop Sci. 18 (2): 331-340.

Rahman, M M, M G Rasul, M A Hossain, K M Iftekharuddaula and H Hasegawa. 2012. Molecular characteization and genetic diversity analysis of rice (Oryza sativa L.) using SSR markers. J. Crop Improv. 26: 244-257.

Ramkumar, G, A K Biswal, K M Mohan, K Sakthivel, A K P Sivaranjanj, C N Neeraja T Ram, S M Balachandran, R M Sundaram and M S Prasad. 2010. Identifying novel alleles of rice blast resistant genes $p i k b$ and pita through allele mining. Intl. Rice Res. Notes. 117: 4185.

Rohlf, F. 2002. NTSYS-pc: Numerical taxonomy and multivariate analysis system, 2.2 edn. Department of Ecology and Evolution, State University of NY, Stony Brook

Schulman, A H. 2007. Molecular markers to assess genetic diversity. Euphytica 158: 313-321.

Siddique, M A, E S M H Rashid, M Khalequzzaman, M K Bashar and L R Khan. 2014. Molecular characterization and genetic diversity in T. Aman landraces of rice (Oryza sativa L.) using microsatellite markers. Thai J. Ag. Sci. 47(4): 211-220.
Siddique, M A, M Khalequzzaman, M M Islam, K Fatema and M A Latif. 2016. Molecular characterization and genetic diversity in geographical indication (GI) rice (Oryza sativa L.) cultivars of Bangladesh. Brazilian J. Bot.: 1-10 (DOI 10.1007/s40415-016-0271-1).

Temnykh, S, G DeClerck, ALukashova, L Lipovich, S Cartinhour and S R McCouch. 2001. Computational and experimental analysis of micro-satellites in rice (Oryza sativa L.), frequency, length variation, transposon associations and genetic marker potential. Genome Res.11: 1441-1452.

Temnykh, S, W D Park, N Ayres, S Cartinhour, N Hauck, L Lipovich, Y G Cho, T Ishii and S R McCouch. 2000. Mapping and genome organization of microsatellite sequences in rice (Oryza sativa L.). Theor. Appl. Genet. 100: 697-712.

Wu, KS and S D Tanksley. 1993. Abundance, polymorphism and genetic mapping of micro-satellites in rice. Mol. Gen. Genet. 241: 225-235.

Zai-quan, C, Y Fu-you, L Ding-qing, Y Teng-qiong, F Jian, Y Hui-jun et al., 2012. Genetic diversity of wild rice species in Yunnan Province of China, Rice Sci. 19 (1): 21-28.

Zheng, K, N Huang, J Bennet and G S Khus. 1995. PCRbased marker assisted selection in rice breeding, IRRI, Manila, Philippines, pp. 16-18. 
